\title{
Al-Tafkir Al-Lughawi Indal Arab
}

\author{
Agussalim Beddu Malla ${ }^{1}$, Usman Ismail ${ }^{2}$ \\ ${ }^{1,2}$ Sastra Arab, Fakultas Sastra, Universitas Muslim Indonesia \\ ${ }^{1}$ agussalim.beddumalla@umi.ac.id
}

\begin{abstract}
Abstrak
Sejak munculnya Agama Islam perhatian terhadap bahasa sangat besar artinya ini disebabkan karena tak satupun pembahasan dalam kajian keislaman baik itu fiqih, tafsir, hadits yang tidak menggunakan bahasa sebagai acuan pertama dan utama. Seiring dengan munculnya ilmu filsafat kedalam kajian Islam maka bahasa mengalami perkembangan yang luar biasa sebagaimana kita saksikan pada abad kedua dan ketiga hijriah, lahirnya para pakar ilmu bahasa yang membahas bahasa dari segala aspek, bukan hanya aspek nahwu, saraf semata tapi sudah masuk ke pembahasan filsafat bahasa bahkan akhirnya munculah macam-macam kajian bahasa seperti sosiolinguistik, psikolinguistik, dll. Hal ini membuat para pengkaji baik bahasa baik di timur tengah maupun di Barat terjadi saling melengkapi.
\end{abstract}

Keywords : Islam, filsafat, bahasa, timur tengah

\section{Introduction}

لقد حاول العلماء منذ ظهر الإسلام وكتابه

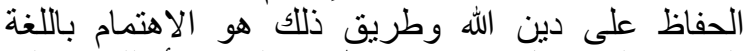

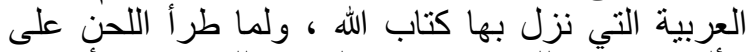

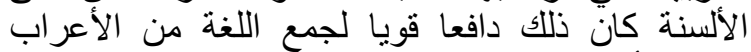

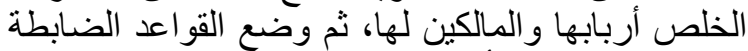

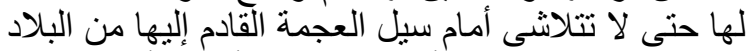

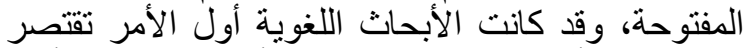

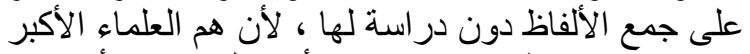

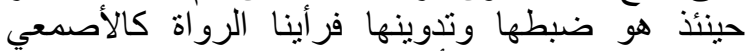

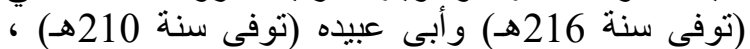

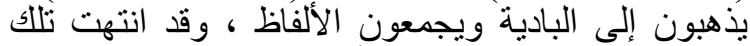

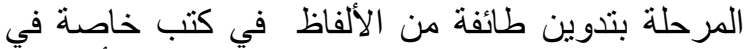

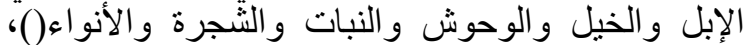

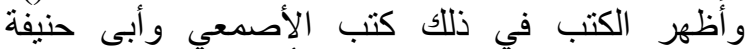

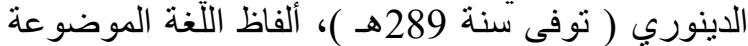

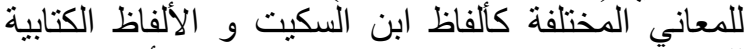

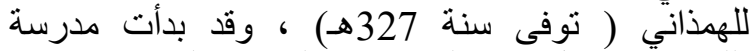
اللغويين تتناول هذه المفردات بالبحث على نحف نحو يجمع الجزئيات وما يتصل بها بها من قصد فص أدبية وتاريخية

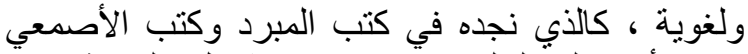

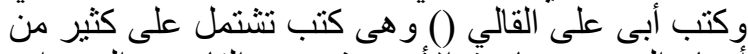

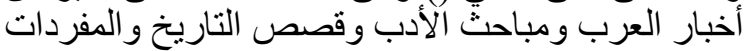
() اللغ وينة

وكان الخليل بن أحمد الفراهيدي (توفى سنة

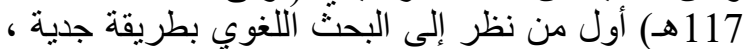
وأول من التفت إلى صلى صلة الدرس الصنوتي بالدي الدر اسات اللغوية الصرفية والنحوية فقد رتب حروف آلهية الهجاء ترنياء صوتيا و على أساس لغوي هو قربها بحسب المخارج فى في
الفم ، فكان منطلقا إلى معرفة خصائص الحروف وصفا وصفاتها.

وكانت الدر اسة اللغوية فى هذه المدة حتى نهاية

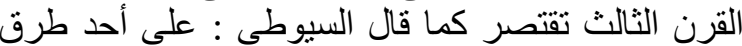

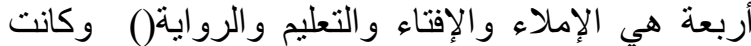

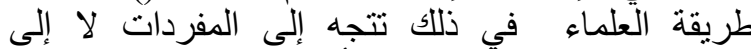

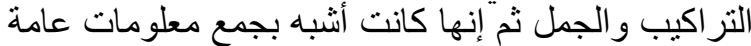

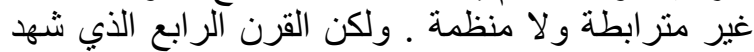

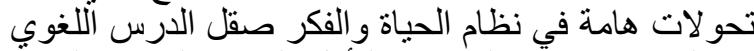

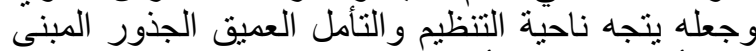

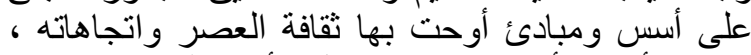
فكتب الأجانب أصبحت في متناول الأبدي العربية تستطيع

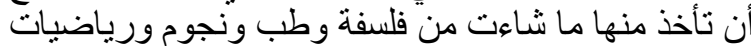

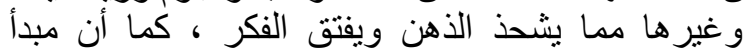

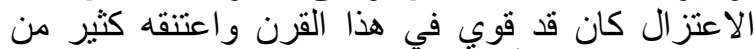

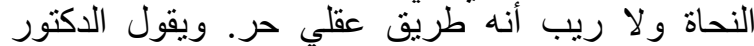

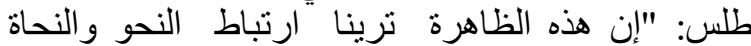
بالحرية الفكرية التي يميل إليها المعتزلة في بحوثهم " . ()

وقد وضع ابن جنى أصولا كثيرة لعلم النحو

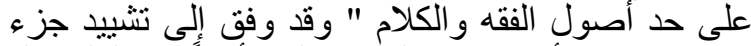

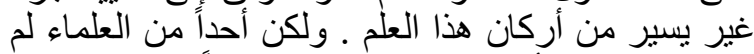

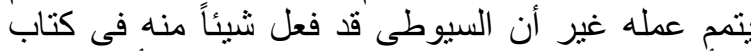
(الأشباه و النظائر) ولكنه قطرة إلى جانب بحر أبى الفتح . ()

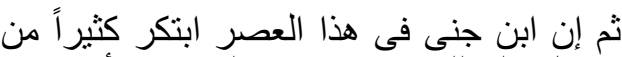

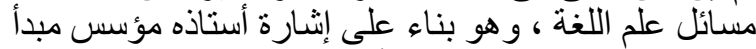

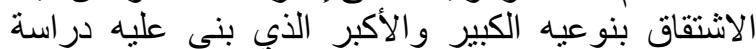

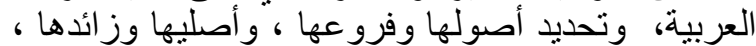

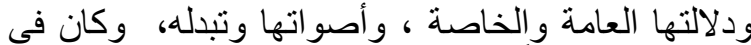
سلوكه هذا مبدعاً حيث ناقش المادة اللغوية كأي واهية باحث 
حديث واستتنج منها ما يثبت براعة العربية وسموها

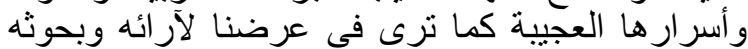

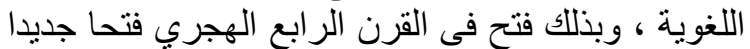

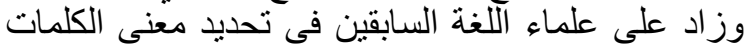
و الإمعان فى الاشتقاق.) ()

و إذا صح أن مصطلح فقه اللغة قد برز في هذا

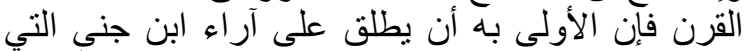

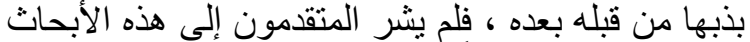

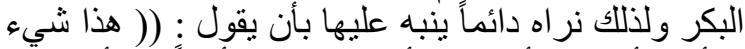

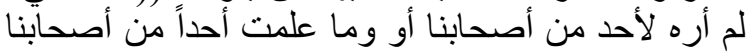

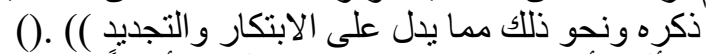

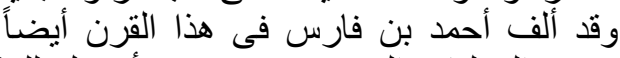

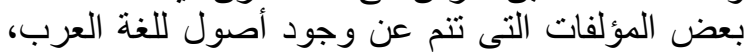

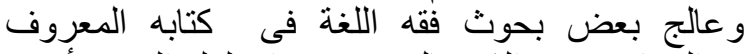

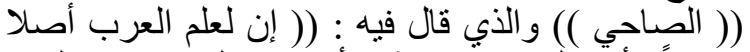

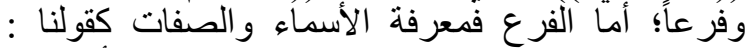

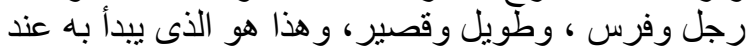
التعلم ، وأما الأصل فالقول على على موضع اللغة ولة وأوليتها

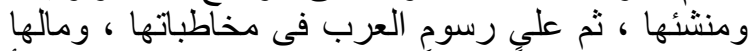

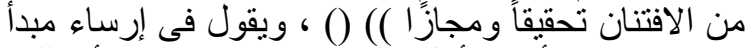

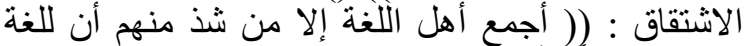

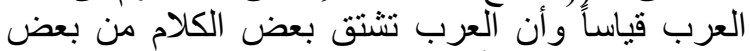

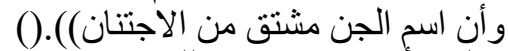

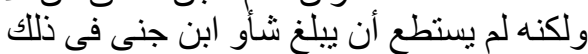

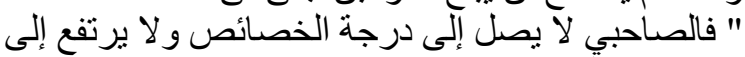

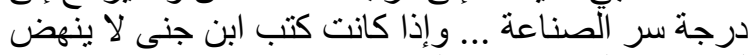

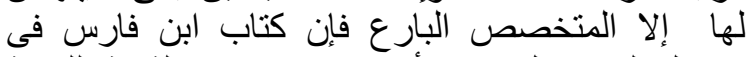
متناول الجميع بل ينبغي أن يكون من كتب الثقافة اللغوية فئ () العامة اللغزة

والحق أن عمل ابن جنى فى الاشتقاق الأكبر

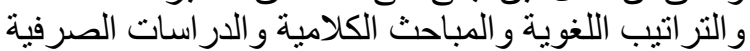

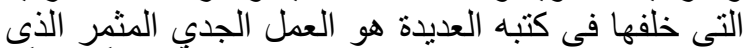
طور مباحث اللغة وجعل لها لأسلوباً جديداً . لألئ

وبذلك تطور " البحث اللغوي وارتقى حتى طئ لإنى

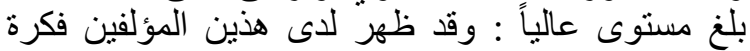

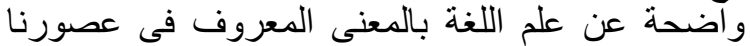

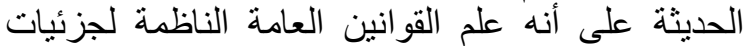

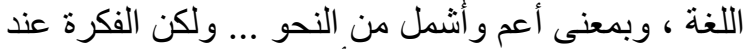

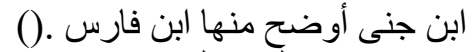

من الطبيعي أن ينشغل الإنسان منذ القديم بلغته الته

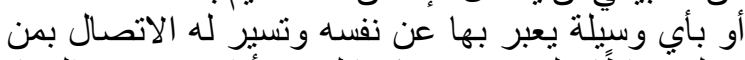

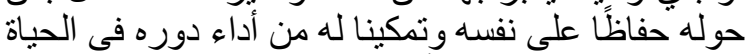

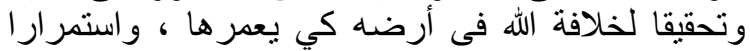

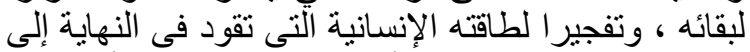

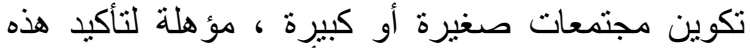

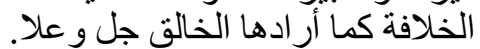

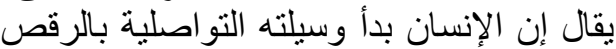

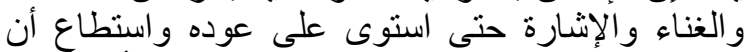

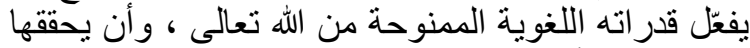

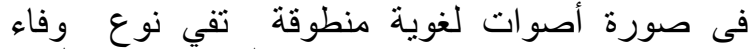

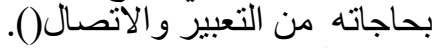

وبمرور الزمن تعمقت هذه القدرات وازداد التعبير

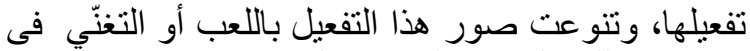
استخدام تللك المنحة الربانية المعروفة بجهاز النطق، النقال
و هكذا دو اليك حتى قدر للإنسان أن يحظى بصورة نطقية

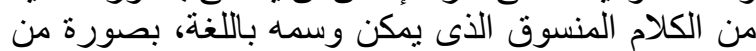
الصور أو بمعنى من المعانى. وبمرور النهات الزمان أيضا

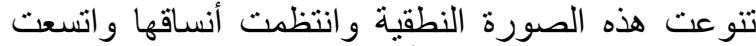

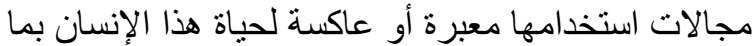

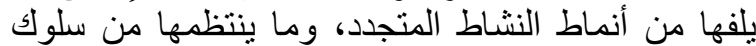

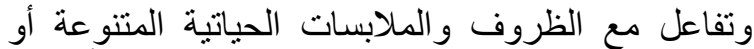
المتغيرة من فترة إلى أخرى.

و هكذا أحسّ الإنسان بأهمية لغته فالتفت إليها وأخذ يحاورها بالأخذ والعطاء، حتى الأنى اتسعت مادتها الأنها

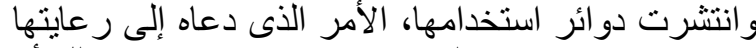

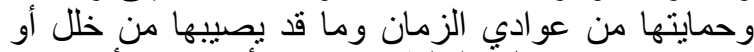

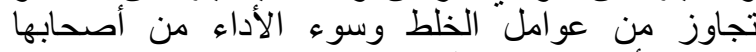

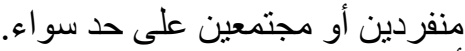

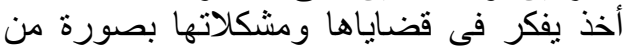

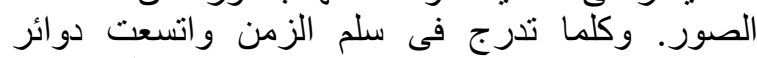
معارفها وتنو عت اهتماماته، تدرج في في طر ائق التفكير فى دئ

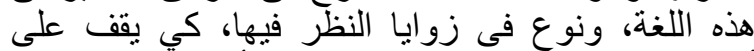

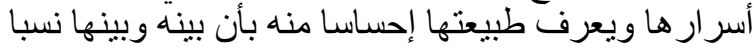

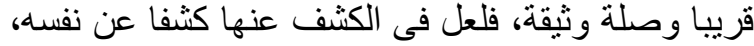
عقلا وفكر ا وسلو كا وملامح إنسانية.

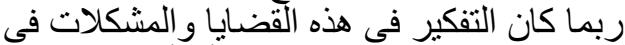

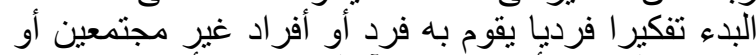

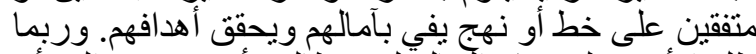

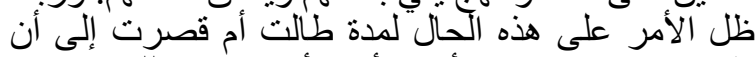

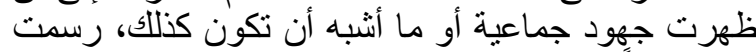

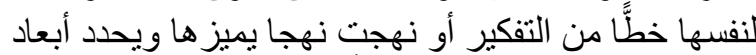
اتجاهاتها فى النظر الواعي نسبيَّا إلى اللغة.

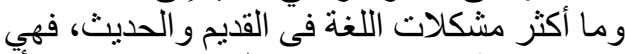

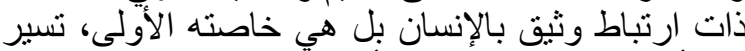

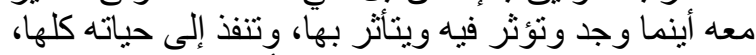

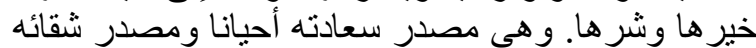
أحيانا أخرى. وهى وهى أيضا وسيلته الأولى في الإنى الاتصال

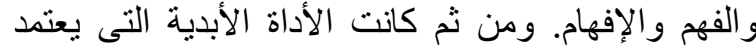

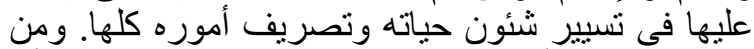
طبيعة البشرية أن تتحو دائما نحو التطور و التقدم ، وأن وان أن وان

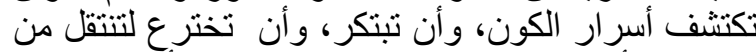

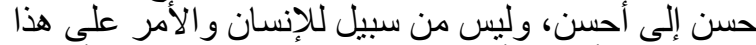
الوضع إلا أن يلجأ إلى اللغة بغية الوصول إلى إلى أهدافه هان

وتحقيق آماله هذه .() الانجا

ولكن هذه اللغة ربما لها لا تسعفه أحيانا، وقد

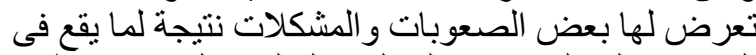

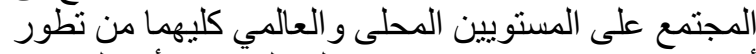

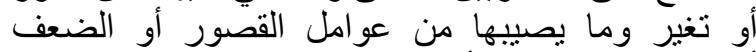
أحيانا، وبخاصة إذا أخذنا فى الحسبان اختلاف اللغات الإن

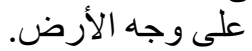

ومعلوم أن اللغة تؤدي دورا مهما في حياتتا

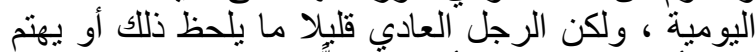

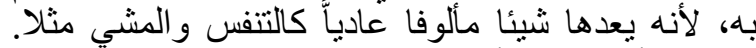

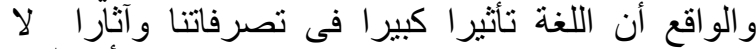
تحصى فى أعمالنا.

\section{Finding and Discussion}


مفهوم اللغة وخصائصها .

هناك تعريفات كثيرة للغة عرفتها الدوائر العلمية

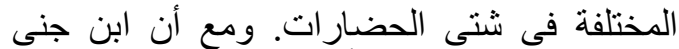

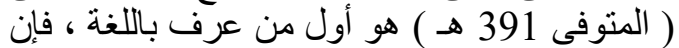
تعريفه بها يثير دهثة الباحثين البعيدين عن تطور

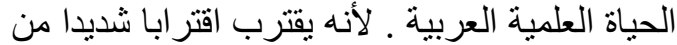
كثير من تعريفات المحدثين ، ولأنه يشتمل معظم

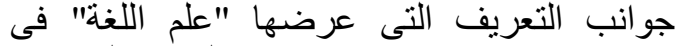
العصر العديث.

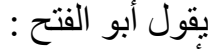

باب القول على اللغة وما هي : ( أُما حدها فإنها

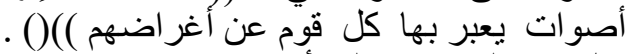

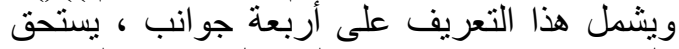

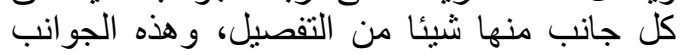
هي:

أن اللغة أصوات ات أنغي

2.

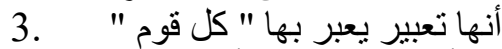

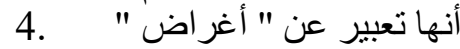

أما أن اللغة (( أصوات)) فلا نكاد نعرف مثل هذا

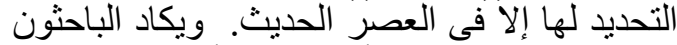

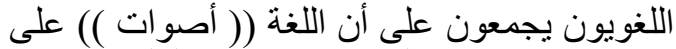

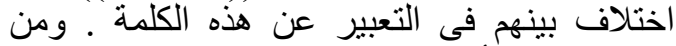

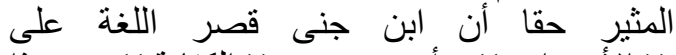

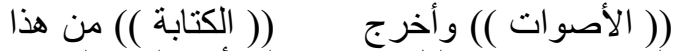

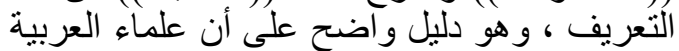

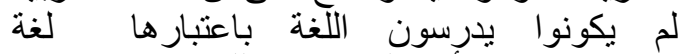

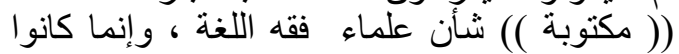

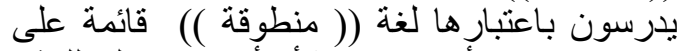

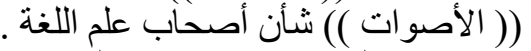

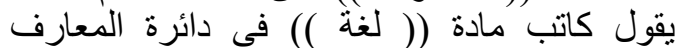

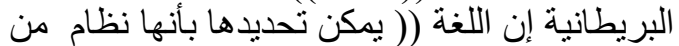

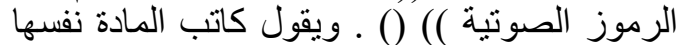
فى دائرة المعارف الأمريكية إن اللغة (( يمكن

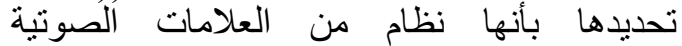

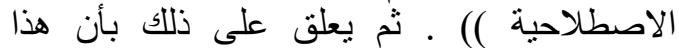

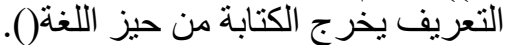

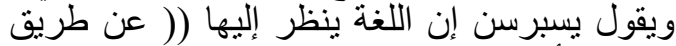
الفم والأذن وليس عن طريق القلم و العين )) (().

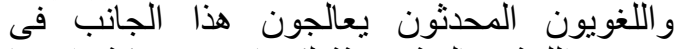

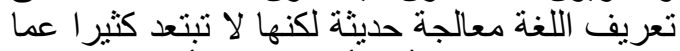

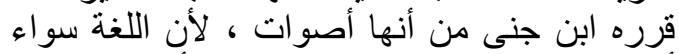

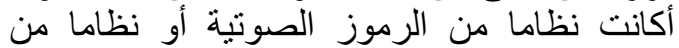

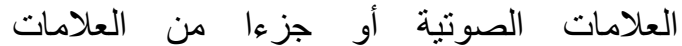

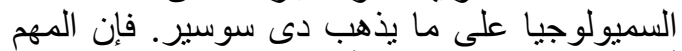
أنها تدرس باعتبار ها (( أصو اتا )) وليس بـاعتبار ها

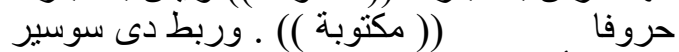

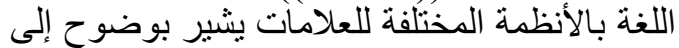

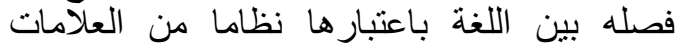

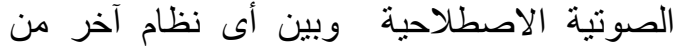

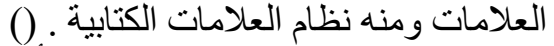
ويتابع فندريس نظرية دى سوسير بقوله : (( أعم تعريف يمكن أن يعرف بنه بـ الكلام أنه نظام من
العلامات )) . . وبعد مقارنة اللغة بالأنظمة الأخرى

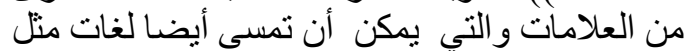

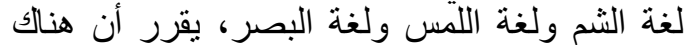
لغة من بين مختلف اللغات الممكنة تطغى على جميع الته

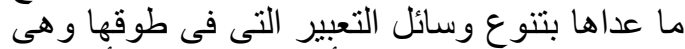
اللغة السمعية التى تسمى أيضا لغة الكائل الكلام أو اللغة (). الملفوظة المغنة

و هذه النقطة فى التعريف بين اللغة بهذا المعنى الذى الذى الذي

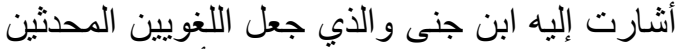

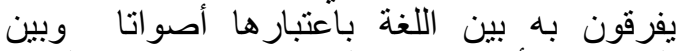

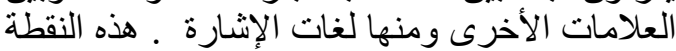

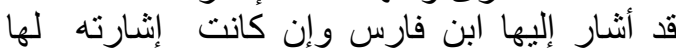

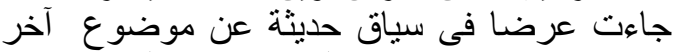

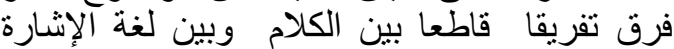

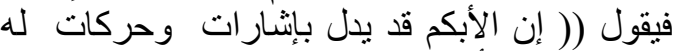

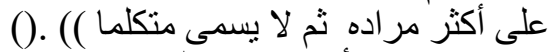

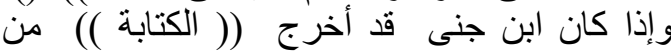

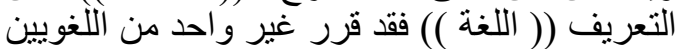

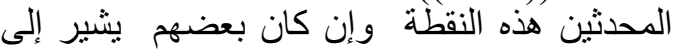

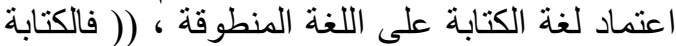

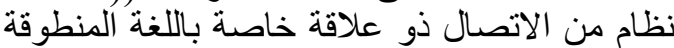

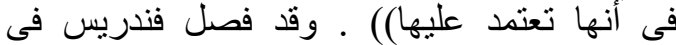

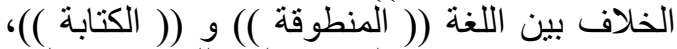

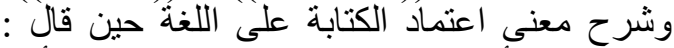
وهكذا نرى أن الاستعمال يتفق مع التقاليد في تأكيد

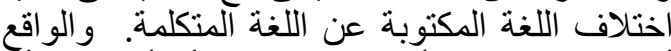

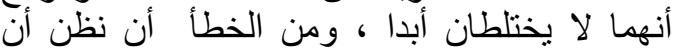

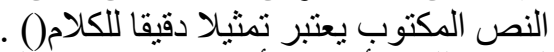

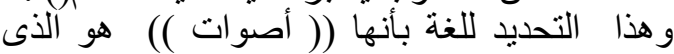

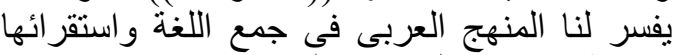

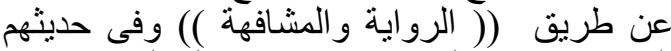

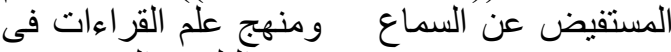

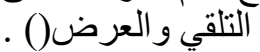

و هذا تعريف دقيق بذكر كثيرًا من الجوانب المميزة

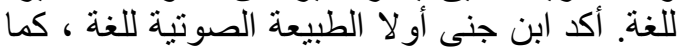

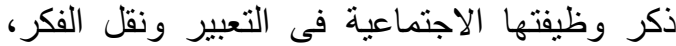
وذكر أيضًا أنها تستخدم فى مجتمع فلكل قوم لغتهم.

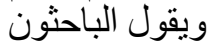

( ) فقه اللغة فى الكتب العربية، د.عبده الر اجحي الباحن

المحدثون بتعريفات مختلفة للغة ، وتؤكد كل هذه النه

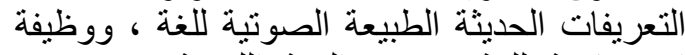
الاجتماعية للغة، وتنوع البنية اللغوية من مجتمع التهية

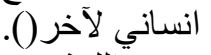

فابن جنى يعرف اللغة بأنها أصوات ، وّاللغة هي الإني

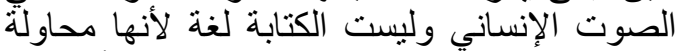
لرسم الصوت الإنساني ـ و إشارته هنا إلى ألى أن اللغة الإنة

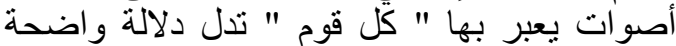

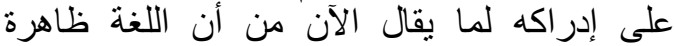

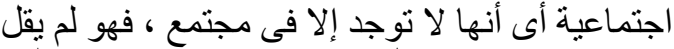

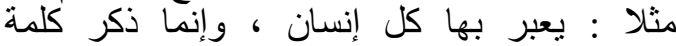

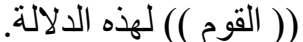

وثمة نقطة أخرى مهمة يثير ها تحديد ابن جنى اللغة ألة التها

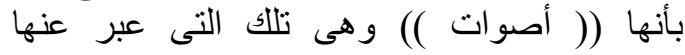


المحدثون بأن اللغة (( نظام من الرموز الصوتية))

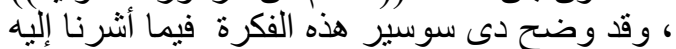

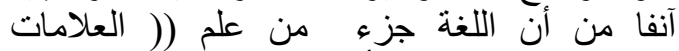
السميولوجيا )) ـ ذللك أن الصوت الصوت الإنسان اللغوي

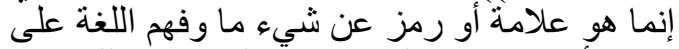

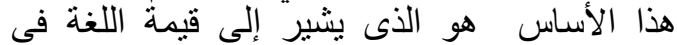

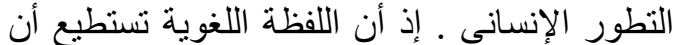

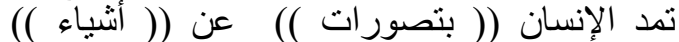
بطريقة لا تمكنه منها أية وسيلة أخرى.

وقد أنشار ابن جنى إلى رمزية اللغة بلى باعنبار ها

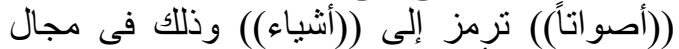

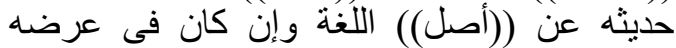

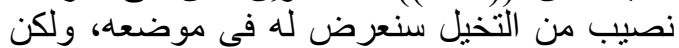
المهم أنه كان يحس إحساسا قويا بما في في اللفظة

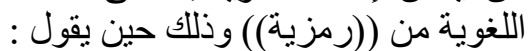

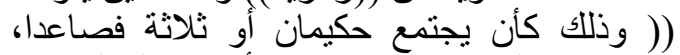

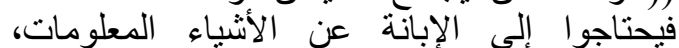

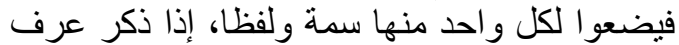

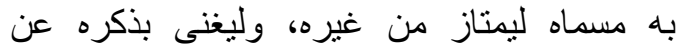

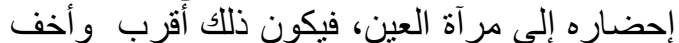

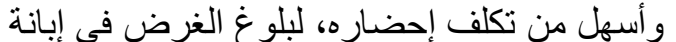

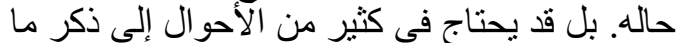

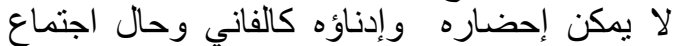

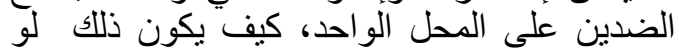
جاز، و غبر هذا مما هو جار في الوالي الاستحالة والبعد

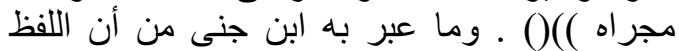

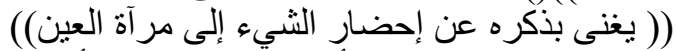
من (Walter

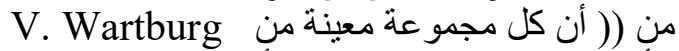

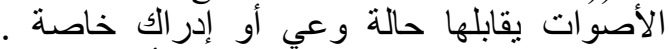

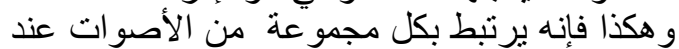

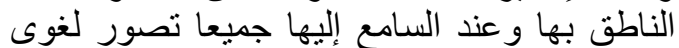

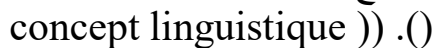

غبر أن ابن جنى كان هو الذى بسط هذا الموضوع

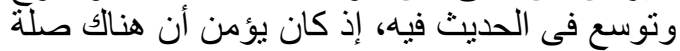

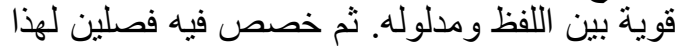

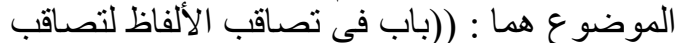
المعانى)) .() و ((باب فى إمساس الألفاظ أثباه

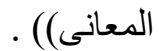

و هكذا يمضى ابن جنى يشرح في استفاضة تلكي العلاقة التى تصورها ابنى بين اللفظ اللغوي باعتباره

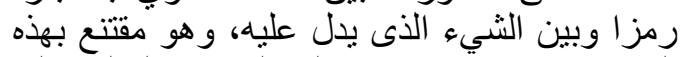

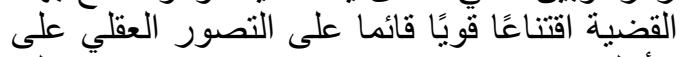

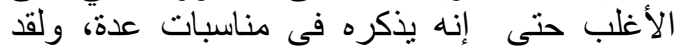
نرجع ما سماه ((الاشتقاق الأكبر )).

لقد أعجب الدكتور صبحي الصالح إعجابا شديدا بما (لإنا

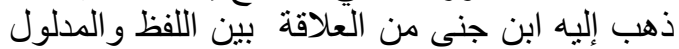

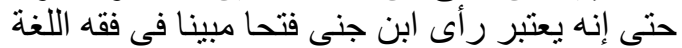
فيقول : (( وإذن فقد أكد هذا العالم الجليل المتأخر

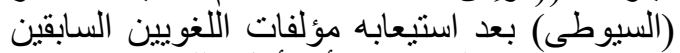

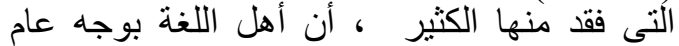

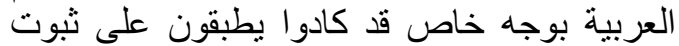
المناسبة الطبيعية بين الألفاظ و المعاني. وبذللك تلاقى مع ابن جنى على صعيد واحد، فكان لا بد لنا من
الاقتتاع بهذه الظاهرة اللغوية التى تعد فتحا مبينا فى () المى

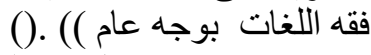

( ) علم اللغة العربية، د.محمود فهمى حجازى، دار ) . (لار

\section{2. وظيفة اللغفة}

أما الجانب الثاني الذى يتضمنه تعريف ابن جنى الذئه

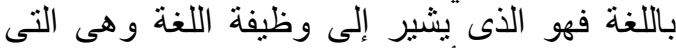

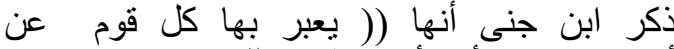
أغراضهم )) أى أن وظيفة اللغة عنده إنما هي (التعبير)() ). (النيا

وتختلف اتجاهات اللغويين المحدثين بين كلمنين

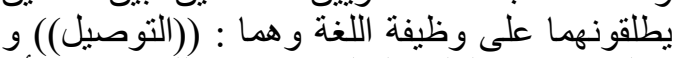

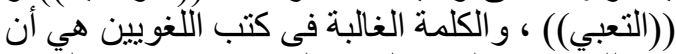

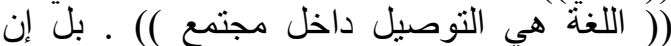

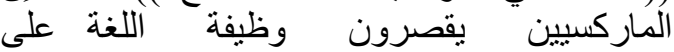

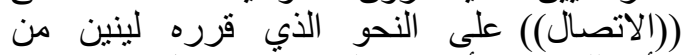
((أن اللغة هي أهم وسيلة فى الاتصال الإنساني)) الإنين .()

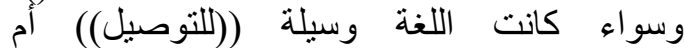

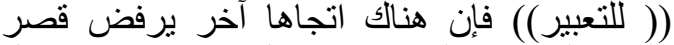
اللغة على هذه الوظيفة، ويقول هذا التان الاتجاه : هل التل

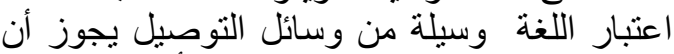

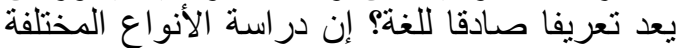

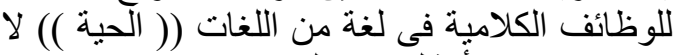
تؤيد أَمثال هذه لتهن التعريفات ولات لتوحي بها.

ويقدم الدكتور السعران أن أمثلة تبين أن النّان الوظيفة الأساسية للغة ليست هي التوصيل أو التعبير ، ومن التئن

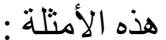

الكلام الانفر ادي ( المونولوج ) ، كالقر اءة الانفر ادية

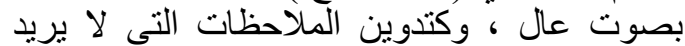

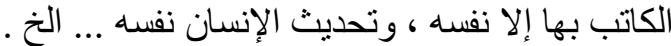
استعمال اللغة فى السلوك الجماعي كالصلاة و الدعاء الاء وغير هما لألاء

استعمال اللغة فى المخاطبات الاجتماعية التى لاتئل التهات تستهدف غاية مثل لغة التحيات ولغة التأدب و الكلام

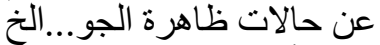

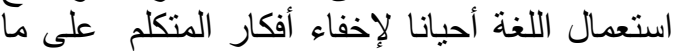

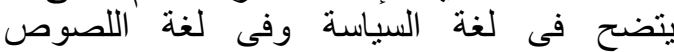
و الخارجين على القانون .

\section{Conclusion}

ثم يعقب الدكتور السعران على ذلك بقوله : وهكذا

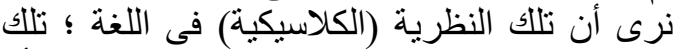

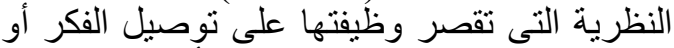

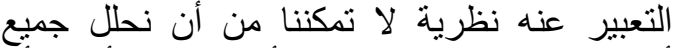

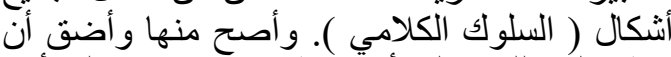
ننظر إلى اللغة على أنها وظيفة اجتماعية على النى أنها

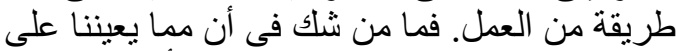

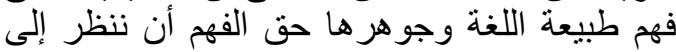
الدور الذى تقوم به فى حياة الفرد وفى حياة الجماعة الفئل 
التى يؤلف بين أفر ادها الحديث بلغة مشتركة، وفى الإنى

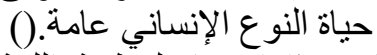

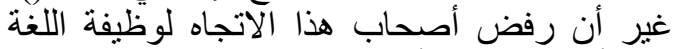

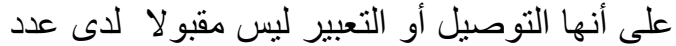

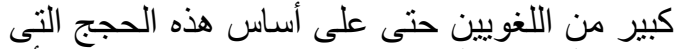

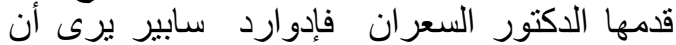
(حديث النفس أو المونولوج) إنما صورة من صور برد التوصيل اللغوي أيضا ذلك أن النئ المتكلم والسامع هنا محققان فى شخص واحد يمكن أن يقال عنه إنه النها يتصل بنفساء)().

\section{References}

عبقري اللغويين، عبد الغفار حامد هلال، دار الفكر

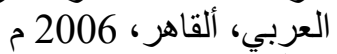

فقه اللغة ، د. محمد المبارك ، ط. جامعة دمثيق الفيق

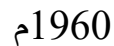

المزهر ، للسيوطي ، دار التراث القاهرة، دون سنة

الصاحبي ، لابن فارس ، تحقيق مصطفى الشويمي

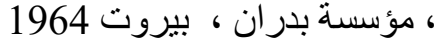

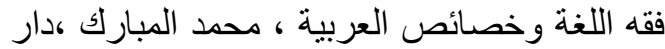

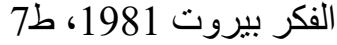

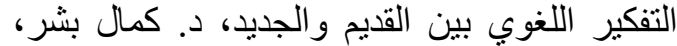
دار غريب ، القاهرة 2005

الخصائص، ابن جني، تحقيق الثيخ محمد على الثى النجار ، طبعة دار الكتب المصرية، التّاهرة 1952.

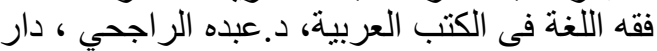
النهضة العربية، بيروت العبد الربية 1979م دار اللغة ، ج.فندريس ، تعريب عبد الحميد الدواخلى و

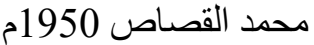

اللهجات العربية فى القراءات القرآنية ، د. د. عبده

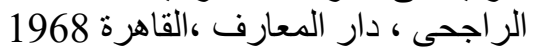

علم اللغة العربية، د.محمود فهمى دجى حجازى، دار القرة غريب القاهرة ، د.ت داري

علم اللغة ، د. محمود السعران

اللغة و المجتمع، د. محمود السعران، دار المعارف دل السعان

بمصر دار المعارف 1963 